\title{
The Farmington consensus statement on editorial guidelines for addiction journals
}

On 14-15 July 1997, editors of 20 journals in the field of addictions convened in Farmington, Connecticut (USA) in a first-of-its-kind meeting, where I had the pleasure of representing Tobacco Control. (The list of journals and their delegates appears in the appendix.) This unique international gathering included delegates from Australia, Canada, France, Italy, Poland, Portugal, The Netherlands, the United Kingdom, and the United States. It was conceptualised and planned by the journal Addiction and its editor-in-chief Griffith Edwards, and was hosted by the journal's regional editor for the Americas, Tom Babor. The motivation for the meeting was the belief that addiction journals have similar needs and concerns, and that they would benefit from greater information exchange and closer collaboration.

The agenda included an opening presentation by Drummond Rennie, a deputy editor of $\mathfrak{f} A M A$, on peer review and bias. Other agenda topics included the needs of journal editors, enhancing the quality of material we publish, enhancing the ethics of journal processes, the changing expectations of libraries, the future of journal publishing (electronic vs print), taking book reviews seriously, pursuing commonality in technical terms used in the field of addictions, and future collaboration among addiction journal editors.

A substantial portion of the meeting was devoted to consideration of editorial guidelines for addiction journals.
A draft consensus statement had been prepared before the meeting, based on a survey of addiction journal editors. After several hours of discussion and constructive debate, and revisions of the original draft document, the group came to agreement on a final statement, which will be referred to here and elsewhere as the Farmington consensus on editorial guidelines for addiction journals.

The Farmington statement is reproduced below. In many places, it is general in nature, reflecting the diversity of viewpoints held by editors and the different processes used by their journals. It is likely that the consensus statement will evolve over time, and that more specificity will be added.

In the coming months, the editors of Tobacco Control will compare our own editorial processes with those recommended by the Farmington statement, and we may modify our practices as a result. As this issue of the journal went to press, our editorial advisory board was scheduled to meet at the 10th World Conference on Tobacco or Health in China in August, and the Farmington statement $\vec{\bullet}$ was on the agenda for the board's feedback. We would be pleased to receive comments on these guidelines from readers of Tobacco Control.

RONALD M DAVIS Editor

\section{The Farmington consensus statement on editorial guidelines for addiction journals}

\begin{abstract}
Preamble
The purpose of this statement is to define the basis for shared identity, commitment and purpose, among journals publishing in the field of psychoactive substance use and associated problems. Our aim is to enhance the quality of our endeavours in this multidisciplinary field. We share common concerns and believe that we do well to join together in their solution. To that end we accede to this document as a statement of our consensus and as basis for future collaboration.
\end{abstract}

\section{Commitment to the peer review process}

1.1 We are committed to peer review and would expect research reports and scientific reviews to go through this process. As regards the extent to which other material will be so reviewed, we see that as a matter for editorial discretion, but policies should be declared.

1.2 Referees should be told that their access to the papers on which they have been requested to comment is in strict confidence. Confidentiality should not be broken by pre-publication statements on the content of the submission. Manuscripts sent to reviewers should be returned to the editor or destroyed.

1.3 Referees should be asked to declare to the editor if they have a conflict of interest in relation to the material which they are invited to review, and if in doubt they should consult the editor. We define "conflict of interest" as a situation in which professional, personal, or financial considerations, could be seen by a fair-minded person as potentially in conflict with independence of judgement. Conflict of interest is not in itself wrong-doing.

1.4 We are committed to enhancing the quality and efficacy of the peer review system that our journals operate. To that end we will, within our own journals, audit the quality of peer review on a continuous basis and where possible provide training to enhance the quality of peer review.

\section{Expectations of authors}

We put the following expectations to authors:

2.1 Authorship: All listed authors on a paper should have been personally and substantially involved in the work leading to the paper.

2.2 Avoidance of double publication: Authors are expected to ensure that no significant part of the submitted mate- 0 rial has been published previously and that it is not $\mathbb{D}$ concurrently being considered by another journal. An exception to this general position may be made when previous publication has been limited to another $\mathbb{D}$ language, to local publication in report form, or to $\mathbb{\mathbb { D }}$ publication of a conference abstract. In all such instances, authors should consult the editor. Authors are asked to provide the editor at the time of submis- $\frac{8}{0}$ sion with copies of published or submitted reports that are related to that submission. Editors are encouraged to develop their own policies regarding the implications of electronic publishing.

2.3 Sources of funding for the submitted paper must be declared and will be published. 
2.4 Conflicts of interest experienced by authors: Authors should declare to the editor if their relationship with any type of funding source might be fairly construed as exposing them to potential conflict of interest.

2.5 Protection of human and animal rights: Where applicable authors should give an assurance that ethical safeguards have been met.

2.6 Technical preparation of papers: Instructions for authors will be published on the technical preparation of papers with the form of these guidelines at the discretion of individual journals.

\section{Formal response to breach of expectations by an author}

Working in collaboration with our authors, we have a responsibility to support the expectations of good scientific publishing practice. To that end each journal will have defined policies for response to attempted or actual instances of duplicate publication, plagiarism, or scientific fraud.

\section{Maintaining editorial independence}

4.1 We are committed to independence in the editorial process. To the extent that the owner or another body may influence the editorial process, this should be declared, and in that case sources of support from the alcohol, tobacco, pharmaceutical, or other relevant interests should be published in the journal.

4.2 We will publish declarations on sources of support received by a journal, and will maintain openness in regard to connections which a journal or its editorial staff may have established which could reasonably be construed as conflict of interest.

4.3 Funding for journal supplements: When we publish journal supplements, an indication will be given of sources of support for their production.

4.4 Refereeing journal supplements: An editorial note will be published to indicate whether they have been peer reviewed.

4.5 Advertising: Acceptance of advertising will be determined by, or in consultation with, the editor of each journal.

\section{Appendix}

Journals (and their delegates) participating in the international meeting on journal editing in the addictions, Farmington, Connecticut (USA), 14-15 July 1997

\section{Addiction}

Griffith Edwards, editor in chief

Thomas Babor, regional editor, Americas

Suzanne Holder, managing editor

\section{Addiction Biology}

Timothy J Peters, editor

Addiction Research

Ernest Drucker, editor

Alcohol

Robert D Myers, editor

Majorie Myers, managing editor

Alcohol and Alcoholism

Abdulla A-B Badawy, editor

Martin Plant, associate editor

Alcoholism Treatment Quarterly

Thomas McGovern, editor

Alcologia

Christina Calzolari Valentino Patussi

\section{Alcoologie}

Jean-Dominique Favre, editor

Gisele Gilkes-Dumas, publisher

\section{Alkoholizm i Narkomania}

Jerzy Jasinski, Office of the editor

Contemporary Drug Problems

Robin Room, editor

Drug and Alcohol Dependence

Chris-Ellyn Johanson, editor

Drug and Alcohol Review

John Saunders, editor

Drugs: Education, Prevention and Policy

Betsy Thom, editor

Fournal of Addictive Diseases

Barry Stimmel, editor

Fournal of Drug Education

Seymour Eiseman, editor

Fournal of Psychoactive Drugs

Richard Seymour, managing editor

Terry Chambers, associate editor

Fournal of Studies on Alcohol

Marc Schuckit, editor

Fournal of Substance Misuse

Moira Plant, editorial advisory board

Olga Maranjian Church, editorial advisory board

Tobacco Control

Ronald M Davis, editor

Toxicodependencias

Joao Salvado Ribeiro, editor 